\title{
Revistas científicas de ciências da comunicação em Portugal: da divulgação do conhecimento à afirmação do Português como língua de pensamento*
}

\author{
Moisés de Lemos Martins**
}

\section{Resumo}

As primeiras revistas científicas de Ciências da Comunicação em Portugal apareceram em meados da década de 1980. Hoje, apesar de a iniciativa editorial se ter diversificado e estendido de Lisboa a outros centros universitários, as publicações em papel não chegam ainda a uma dezena. A estas somam-se algumas revistas exclusivamente online, que têm contribuído para ampliar o âmbito dos enfoques temáticos. Neste artigo, procuramos fazer um inventário das revistas que se publicam em Portugal, reflectindo em simultâneo sobre as suas principais fragilidades, por um lado a falta de rigor na periodicidade, por outro a tendência para a publicação de textos noutras línguas que não apenas o Português. É também objectivo deste trabalho sustentar a importância da inscrição destas publicações nos principais índex internacionais, tanto para afirmar a investigação realizada em Portugal, como para promover o Português como língua de pensamento.

Palavras chave: Comunicação. Revistas. Internacionalização. Investigação. Língua Portuguesa.

* Estudo elaborado no quadro do Fórum "Revistas Científicas de Ciências da Comunicação no espaço ibero-americano" e apresentado no Congresso da CONFIBERCOM, realizado em agosto de 2011, em São Paulo. Obs.: A revista manteve a escrita na língua original (português de Portugal).

** Professor Doutor Catedrático de Ciências da Comunicação, Curso de Doutorado em Estudos Culturais, Centro de Estudos Comunicação e Sociedade, Universidade do Minho - Braga, Portugal. Director do Centro de Estudos Comunicação e Sociedade (CECS), da revista Comunicação e Sociedade e do curso de doutoramento em Estudos Culturais. Presidente da SOPCOM - Associação Portuguesa de Ciências da Comunicação, e também da LUSOCOM - Federação Lusófona de Ciências da Comunicação. Doutor em Sociologia pela Universidade de Ciências Humanas de Estrasburgo. Autor de Crise no Castelo da Cultura - Das Estrelas para as Telas (São Paulo: Annablume, 2011).E-mail: moiseslmartins@gmail.com 


\section{Communication Sciences journals in Portugal: from knowledge} diffusion to the assertion of Portuguese as a language of thought Abstract

The first scientific journals of Communication Sciences in Portugal appeared in the mid-1980s. Today, although the editorial initiative has been diversified and extended from Lisbon to other universities, the paper publications do not reach even a dozen. To these are added some journals exclusively online, which have contributed to expand the scope of the thematic focuses. Within this paper, we tried to make an inventory of journals that are published in Portugal, at the same time reflecting on their main weaknesses: the lack of rigour in periodicity in some cases and in others the tendency to publish texts in other languages than Portuguese only. It is also objective of this study to support the importance of registering these publications in the most relevant international index, and to assert the research carried out in Portugal, as well as to promote the Portuguese as a language of thought.

Key words: Communication. Journals. Internationalization. Research. Portuguese Language.

\section{Revistas científicas de Ciencias de la Comunicación en Portugal: de la divulgación do conocimiento del portugués como lengua de expresión de pensamiento}

\section{Resumen}

Las primeras revistas científicas de Ciencias de la Comunicación en Portugal aparecieron a mediados de la década de 1980. Hoy en día, aunque la iniciativa editorial se haya diversificado y extendido desde Lisboa a otras universidades, las publicaciones impresas no llegan ni una docena. A estas se suman algunas revistas exclusivamente online, que han contribuido a ampliar el alcance de los ejes temáticos. En este artículo, tratamos de hacer un inventario de las revistas que se publican en Portugal y, al mismo tiempo, de reflexionar sobre sus principales debilidades: la falta de rigor en la periodicidad en algunos casos y en otros la tendencia a publicar textos en idiomas distintos al portugués. Otro de los objetivos de este estudio es sustentar la importancia de la inscripción de estas publicaciones en los índices internacionales más importantes para afirmar la investigación llevada a cabo en Portugal, así como para promover el portugués como lengua de expresión de pensamiento.

Palabras clave: Comunicación. Revistas. Internacionalización. Investigación. Lengua Portuguesa.

\section{Nota introdutória - aspectos metodológicos}

osso propósito foi fazer a radiografia do universo das revistas de Ciências da Comunicação em Portugal. Por essa razão, cruzamos diversas fontes de informação. 
Num primeiro momento, realizamos o rastreio dos websites dos Departamentos e dos Centro de investigação de Ciências da Comunicação das principais universidades e politécnicos do país. Depois, sempre que houve necessidade de colmatar a insuficiência dos dados de domínio público nestes espaços online, foram directamente contactadas, umas vezes por correio electrónico, outras por telefone, os directores de revistas, Departamentos ou Centros de investigação.

\section{Ciências da Comunicação: área científica de ensino e publicação}

Sendo a comunicação matéria transversal a diferentes ciências humanas e sociais e fenómeno de que desde sempre, directa ou indirectamente, se ocupou o pensamento filosófico, é compreensível que seja difícil balizar o seu nascimento como campo científico delimitado. No entanto, é comum situar-se na década de 1950 a formalização das Ciências da Comunicação como domínio de estudo, investigação e ensino, uma vez que foi por esta altura que se constituíram os primeiros departamentos de Ciências da Comunicação em universidades de alguns países. Por esta razão, apenas a partir da segunda metade do século 20 começaram a ser publicadas as primeiras revistas científicas especificamente vocacionadas para a divulgação do conhecimento nesta área.

Em Portugal, a fundação das Ciências da Comunicação no meio académico é ainda mais tardia. Na verdade, só em 1979 aparece, em Lisboa, o primeiro curso de graduação em Comunicação Social, por iniciativa do então designado Departamento de Comunicação Social da Faculdade de Ciências Sociais e Humanas da Universidade Nova de Lisboa. Este núcleo académico - que passou a chamar-se Departamento de Ciências da Comunicação - é reconhecido pelo lançamento efetivo desta área científica no país. A este Departamento estão associados, por sua vez, três outros importantes acontecimentos: a criação do primeiro curso de pós- graduação, a constituição do Centro de Estudos de Comunicação e Linguagens (CECL) e o lançamento da Revista de Comunicação e Linguagens (respetivamente, o mais antigo centro de Comunicação em Portugal e a primeira revista científica desta área). 
Com uma atuação em regime de exclusividade nos primeiros anos - dado que só um pouco mais tarde é que outras universidades passaram a apostar na Comunicação como área de estudos autónoma - o Departamento de Ciências da Comunicação da Universidade Nova de Lisboa foi particularmente oportuno neste investimento, beneficiando de uma conjuntura de expansão dos media em Portugal. A abertura de novos órgãos de comunicação social - designadamente, o lançamento de novos jornais, a abertura dos canais privados de televisão, a legalização de mais de três centenas de rádios locais e regionais -, assim como a diversificação das profissões ligadas à comunicação, contribuíram significativamente para o aumento do número de pessoas interessadas na formação superior em jornalismo, relações públicas, publicidade e comunicação audiovisual. A par deste fenómeno de desenvolvimento do ensino, que compreendeu a criação de outros cursos de Comunicação nos principais centros universitários do país e a sua extensão a unidades de ensino superior mais pequenas, como os institutos politécnicos, foram, finalmente, criadas condições para a produção de conhecimento em centros de pesquisa especializados e para a difusão da investigação em publicações nacionais.

\section{Revistas de publicação em papel}

O primeiro número da Revista de Comunicação e Linguagens, publicada pelo Centro de Estudos de Comunicação e Linguagens, foi lançado em Março de 1985. Tratou-se de um número sobre "as máquinas censurantes modernas", um tema que anunciava já a tendência que a revista teria para o tratamento da comunicação no sentido amplo do termo, e não para o seu estreitamento nos estudos jornalísticos strictosensu. Em pouco mais de 25 anos, foram publicados 41 números ${ }^{1}$, dedicados a questões que passaram pelos debates sobre o "Moderno e o Pós-Moderno" (números 6/7), as "Tendências da Cultura Contemporânea" (número 28) e "A Cultura das Redes" (número extra publicado em Maio de 2002), e também sobre "Televisão" (número 9), "Ética e Comunicação" (números 15/16) e "Imagem e Vida" (número 31).

\footnotetext{
${ }^{1} \mathrm{O}$ número 42 está no prelo, à altura da redacção final deste texto.
} 
Servindo-se do site do Centro de Estudos de Comunicação e Linguagens como sua própria montra (http:/www.cecl.com.pt/ rcl), a revista não está, porém, disponível online. Todos os seus conteúdos são exclusivamente divulgados em versão impressa, actualmente editados pela Editora Relógio d'Água. À venda nas principais livrarias do país, a Revista de Comunicação e Linguagens também não tem loja online, podendo, por isso, dizer-se que o seu acesso está condicionado às cadeias de distribuição tradicionais.

A segunda revista mais antiga no panorama nacional é a revista Comunicação e Sociedade, editada pelo Centro de Estudos de Comunicação e Sociedade (CECL), da Universidade do Minho. Publica-se desde 1999, tem actualmente uma periodicidade estabelecida de dois números por ano e soma uma vintena de volumes publicados. Tratando de temas como "Comunicação da Ciência” (número 6), "Comunicação Estratégica” (número 8), "Regulação dos Media em Portugal" (número 11) e "Publicidade - discursos e práticas" (número 19), esta publicação dedicou também um volume especificamente aos "50 anos do Telejornal em Portugal” (número 15), na sequência de uma iniciativa de celebração, em 2009, com o operador de serviço público de televisão, do meio século de informação televisiva no país. Embora não esteja também totalmente disponível online, a revista Comunicação e Sociedade (http://www.comunicacao.uminho.pt/ cecs/pubicacoes), que é editada pela Editora Húmus, tem cada um dos volumes disponíveis para consulta, a partir do site do Centro de Estudos de Comunicação e Sociedade, onde é possível visualizar o respectivo índice.

Em 2001, começou a publicar-se também uma revista de comunicação e cultura, na Universidade Lusófona de Lisboa, a Caleidoscópio, que editou até 2011, 10 números. Com parca existência online, é difícil acompanhar o percurso temático desta revista, que também não tem actualmente qualquer forma de acesso online - nem ao seu arquivo temático, nem aos conteúdos de cada edição. Inscrevendo-se, porém, na iniciativa do Departamento de Ciências da Comunicação, Artes e Tecnologia daquela Universidade, a revista tem procurado tratar temas que cruzam a comunicação com o domínio das artes digitais. 
Durante os anos 2000, outros títulos se juntariam a este cenário. Em 2002, por exemplo, apareceu a revista Trajectos, uma publicação de Comunicação, Cultura e Educação. Publicada pelo ISCTE - Instituto Universitário de Lisboa, esta revista lançou já 18 números, também eles de muito difícil consulta online, por não existir, neste caso, sequer um site com o arquivo dos números editados. Publicada hoje pela Editora Fim de Século, a revista tratou ao longo dos últimos nove anos temas como "Media, Públicos e Espaço Público" (número 10), "Os Jornalistas Portugueses" (número 12), "Arte e Política" (número 16) ou, mais recentemente, "Internet e participação cívica" (número 18).

Também em 2002, e na sequência da criação do Centro de Investigação Média e Jornalismo, em 1997, juntou-se a este panorama a revista Media e Jornalismo, uma publicação que se afirma, como se diz no site de apresentação ${ }^{2}$, «como um fórum promotor de discussão qualificada não só na comunidade académica mas também entre todos os que se interessam pelos media e pelo jornalismo nas sociedades contemporâneas». Com 19 números publicados, sobre temas que vão desde "Media e Desporto" (número 4), à "Inclusão e Participação Digital” (número 19), passando por números temáticos dedicados, por exemplo, às "Mulheres e os Media" (número 5), à "Europa e os Media” (número 14) e ao "Género, Media e Espaço Público" (número 15), a revista Media e Jornalismo é a única revista científica em papel com todos os seus conteúdos disponíveis online, a partir do site do centro de investigação a que pertence.

Mais recentemente, em 2005 e em 2006, começaram a publicar-se duas outras revistas: a Comunicação Pública, da responsabilidade da Escola Superior de Comunicação Social de Lisboa, com oito números publicados até ao momento; e a revista Comunicação e Cultura, editada pelo Centro de Estudos de Comunicação e Cultura, da Universidade Católica Portuguesa, e pela Editora Quimera. Quer uma quer outras revistas, publicaram menos de uma dezena de números, dos quais apenas os resumos dos textos integrantes estão disponíveis online. No que concerne a temáticas,

\footnotetext{
${ }^{2}$ http://www.cimj.org/index.php?option $=$ com_content $\&$ view $=$ article $\&$ id $=38$ \&Itemid $=32$
} 
se a primeira, a revista Comunicação Pública, tem uma actuação em torno da mediatização de determinados acontecimentos, a segunda, a revista Comunicação e Cultura, tem vocação para a edição de textos particularmente ligados às Indústrias Culturais. Com efeito, ao contrário da revista da Escola Superior de Comunicação Social de Lisboa - que não identifica um tema para cada número -, a revista Comunicação e Cultura tem-se dedicado a temas como o "Lobbying e o Marketing Político" (número2), "A Mediatização da Dor" (número 5) e os "Intelectuais e os Media" (número 7).

No conjunto, são sete as revistas científicas ${ }^{3}$ que se publicam em Portugal, em versão papel. Nem todas são suficientemente divulgadas online, tendo algumas delas, inclusive, insuficiente informação na Internet, como sejam a Trajectos e a Caleidoscópio. De acordo com a informação disponibilizada pelas próprias publicações, quatro destas revistas estão inscritas no Latindex - o Sistema Regional de Informação em Linha para Revistas Científicas da América Latina, Caraíbas, Espanha e Portugal -, a saber a Revista de Comunicação e Linguagens, a revista Comunicação e Sociedade, a revista Media e Jornalismo e a revista Trajectos.

Não estão divulgados dados muito concretos sobre as taxas de venda destas publicações, mas crê-se que o número de exemplares vendidos é consideravelmente baixo. Nalguns casos, é mesmo verdadeiramente difícil encontrar os volumes destas revistas à venda nas principais livrarias do país. Pode dizer-se, com propriedade, que as cadeias de distribuição são frágeis e que estas publicações revelam genericamente pouco potencial comercial. Sendo de grande interesse científico, quer genericamente para os centros de investigação a que estão associadas, quer para os investigadores, em particular, que nelas publicam, as revistas portuguesas de Ciências da Comunicação são, sem dúvida, insuficientemente divulgadas na comunidade científica nacional e, muitas vezes, a sua expressão internacional é tímida e insignificante. Por sua vez, a divulgação

\footnotetext{
${ }^{3}$ Existe uma oitava publicação, embora de carácter menos sistemático e de informação muito reduzida. Referimo-nos aos Cadernos Mediáticos, revista editada pela Universidade Fernando Pessoa (Porto), não se conhecendo praticamente nenhuma indicação online, embora se saiba estar aberta, em 2011, a chamada para submissão de artigos ao número nove desta publicação.
} 
que delas é feita noutros países acontece quase exclusivamente por via dos relacionamentos interpessoais entre investigadores, e praticamente nunca de forma comercial.

\section{Revistas de publicação online}

No domínio das publicações online, o panorama das revistas portuguesas não é mais vasto, ainda que, pelo seu carácter electrónico, se possa admitir que a divulgação seja muito mais ampla nestes casos. À semelhança da maior parte das revistas em papel, as revistas electrónicas são criações dos anos 2000, associadas à actividade dos centros de investigação desta área específica.

No espectro online, a revista Interact - Revista Online de Arte, Cultura e Tecnologia, produzida pelo Centro de Estudos de Comunicação e Linguagens (CECL), partilha com a Recensio, do centro de investigação LabCom, da Universidade da Beira Interior, a condição de mais antiga publicação. Publicou-se pela primeira vez em 2000, contando em 2011 com 18 números lançados em linha (http://interact.com.pt). O objectivo da publicação é, de acordo com a sua apresentação no site, "a reflexão e a discussão em torno de temáticas importantes do pensamento contemporâneo, o acompanhamento crítico de acontecimentos e práticas culturais e artísticas e o incentivo ao trabalho de experimentação com as tecnologias digitais e as redes de informação”. Em termos temáticos, tem especial abertura para o debate entre a cultura e a cibercultura e entre práticas tradicionais de expressão, como o ensaio, e práticas mais vocacionadas para a hipertextualidade e a interactividade.

Embora se tenha publicado em papel, de 2000, data da fundação, até 2006, a revista Observatório (Obs*) é talvez, hoje, a mais internacional das revistas online portuguesas. Está indexada na SciverseScopus, assim como no Latindex, no Scielo e no EBSCO. Publicou 11 números em papel, dedicados a temas como "Os media nas regiões" (número 2), "Televisão, qualidade e serviço público" (número 6) e "Televisão Interactiva: avanços e impactos" (número 11). Enquanto edição online, passou a publicar-se três vezes por ano, estando disponível em Open Access (http://www.obercom.pt/ content/139.cp3), com o intuito de permitir "aos autores a máxima 
exposição pública dos seus trabalhos" (como se refere no texto de abertura de cada volume).

Um dos centros de investigação que mais têm investido neste tipo de publicações tem sido o LABCOM, da Universidade da Beira Interior. A partir desta unidade de investigação publicam-se quatro revistas. A Recensio (http://www.recensio.ubi.pt/index.php3), fundada em 2000, define-se como uma Revista de Recensões de Comunicação e Cultura e publica em diversas áreas temáticas, da Comunicação Digital ao Cinema, passando pelas Políticas de Comunicação, o Jornalismo, os Estudos Televisivos e Estética, Arte e Design. A DOC Online (http://www.doc.ubi.pt/), por seu lado, é uma Revista Digital de Cinema Documentário, que desde 2006, publicou 10 números. Editada pelo mesmo centro de investigação, aceita sobretudo estudos sobre cinema, estando particularmente ligada à actividade dos investigadores nesta área.

Com significativo dinamismo, o LABCOM tem também publicado, desde 2007, a revista Estudos de Comunicação/CommunicationStudies (http://www.ec.ubi.pt/ec/09), uma publicação bilingue, que privilegia a edição de textos em português e em inglês. Publica-se desde 2007, tendo sido já editados nove números. Bem mais modesta tem sido a expressão da Rhêtorikê, uma revista especializada em Retórica e Argumentação, que, desde 2008, publicou apenas três números.

Para além destas publicações, está em preparação o lançamento de uma revista electrónica, especialmente vocacionada para a publicação de trabalhos de pós-graduação, sobretudo de trabalhos preparatórios de Doutoramento. Esta iniciativa está actualmente em desenvolvimento no seio do Grupo de Trabalho de Jovens Investigadores da SOPCOM - Associação Portuguesa de Ciências da Comunicação, que está a projetar esta nova revista para lançamento em 2012. Sem pretensão comparativa, pode talvez admitir-se que os propósitos desta publicação serão, de algum modo, equivalentes aos da revista brasileira E-Compós, pretendendo-se que sirva particularmente para a divulgação de trabalhos de investigadores em início de carreira, quer sejam estudantes de pós-graduação, quer sejam investigadores de projectos coletivos, suportados por bolsas de investigação. 


\section{Fragilidades das revistas portuguesas}

Dada a dimensão ainda relativamente reduzida da comunidade científica portuguesa de Ciências da Comunicação, não é legítimo considerar que o número de publicações científicas actualmente existentes seja insuficiente. $\mathrm{Na}$ verdade, atendendo à produção nacional, pode talvez admitir-se como ajustada à atividade dos investigadores portugueses a oferta de publicações disponíveis para a divulgação científica. Por outro lado, ainda que possam reclamar-se publicações em áreas emergentes como os média interactivos, deve reconhecer-se que está, de alguma maneira, assegurada a publicação em todas as áreas de conhecimento deste campo científico, porque, se é certo que existem pelo menos duas publicações mais especializadas, casos da DOC Online e da Rhêtorikê, a maior parte das revistas tem um carácter abrangente e de ampla abertura temática.

Não obstante este aparente contexto de suficiência, as revistas científicas de Ciências da Comunicação que se publicam em Portugal encerram um conjunto de fragilidades que tem comprometido a sua definitiva afirmação como publicações de referência. Com efeito, dando provas de uma certa estabilidade, na medida em que se publicam de forma mais ou menos ininterrupta, nalguns casos há mais de uma década, as revistas portuguesas têm ainda genericamente uma divulgação insuficiente.

Uma das mais sérias fraquezas dos títulos portugueses é a dificuldade que têm em assegurar a periodicidade dos números editados. Embora admitindo algumas excepções, pode dizer-se que a maioria dos títulos, sobretudo em papel, regista, pontual ou regularmente, problemas com a periodicidade dos volumes, muitas vezes justificados pela falta de equipas de apoio técnico e logístico à produção. Não raras vezes, o processo de recepção dos artigos, distribuição por revisores, avaliação e edição fica integralmente a cargo dos editores, que dificilmente podem ter como actividade exclusiva tarefas desta natureza.

Outra fragilidade frequente das revistas portuguesas prende-se com a falta de mecanização dos processos de revisão de pares. Nos casos em que existe este procedimento, por certo a maioria, as acções 
de apreciação fazem-se ainda em moldes relativamente rudimentares, muito distantes das rotinas de outras revistas internacionais.

Não sendo os únicos motivos, estes dois aspectos justificam em boa parte a razão pela qual as revistas portuguesas não têm factor de impacto conhecido nem ocupam lugar de destaque nos índex internacionais de referência. Como referimos antes, apenas a revista Observatório $(\mathrm{Obs} *)$ tem inscrição em alguns sistemas de indexação, estando quatro outras igualmente inscritas no Latindex, o que será manifestamente insuficiente para afirmar o valor destes títulos.

A par destes embaraços, as revistas portuguesas padecem,em termos gerais, de um problema de fraca penetração e reconhecimento internacional. Este aspecto é especialmente relevante, na medida em que dá conta, também, da fraca afirmação das revistas portuguesas de Ciências da Comunicação nos países de expressão portuguesa e castelhana, nomeadamente no Brasil e em Espanha, onde é expectável que o português seja uma Língua privilegiada de trabalho e de documentação. Acontece, porém, que apesar de serem conhecidas nestes territórios de proximidade cultural, as revistas portuguesas têm ainda um papel insignificante, pelo menos muito distante do desejável, na referenciação de trabalhos académicos.

Em sintonia com esta preocupação, uma das questões mais sensíveis no tocante à produção das revistas portuguesas, prende-se, curiosamente, com uma certa ambiguidade relativamente ao idioma de publicação. $\mathrm{Na}$ verdade, tem-se registrado uma tendência progressiva para publicações linguisticamente híbridas, que aceitam a submissão e a publicação de textos noutras línguas, que não exclusivamente o português, como tem sido o caso do castelhano, francês e inglês. Apesar de ser compreensível esta opção, como estratégia para a difusão mais alargada da produção nacional, não deixa de constituir um sinal de reconhecida debilidade, na medida em que confere às publicações um carácter de vulnerabilidade perante a força expressiva de outras línguas.

\section{Da internacionalização à promoção da Língua Portuguesa}

Muitas razões justificam a necessidade de promover a edição de revistas científicas portuguesas. Existe, porém, uma que deve- 
ria tomar-se como primordial: a afirmação da língua portuguesa como língua de pensamento e de conhecimento. Amorosamente indecisa e duvidando, a identidade lusófona sonha, todavia, com um parentesco histórico, cultural e linguístico, entre os países de expressão portuguesa (Baptista, 2000; Brito e Martins, 2004; Cabecinhas e Cunha, 2008). E falar de sonho, quando nos referimos ao destino das nossas comunidades, não é dizer pequena coisa, uma vez que o real, todo o real, começa por ser um sonho na cultura, e só depois se torna uma concretização cultural. Ora, pelo menos no que respeita às comunidades científicas lusófonas, trata-se de um sonho ver rebatidas as fronteiras, todas as fronteiras de linha plena e contínua, e de as ver substituídas pelos limites imprecisamente espacializáveis da tradição e do destino comuns, com a história cultural destes distintos países a assinalar sempre a co-presença do mesmo e do outro no caminho que desejamos percorrer em comum. Poderíamos dizer que, num certo sentido, essa é a nossa utopia de comunicação (Martins, 2011).

Nos dias de hoje, ao autonomizar-se como variável dominante no mundo, a globalização fraccionou as sociedades transcontinentais, cujos projectos todavia a precederam: o Brasil e os Estados Hispânicos convergem no Mercosul; por sua vez, a Francofonia, a Comunidade Britânica, a Lusofonia e o Panarabismo desenvolveram linhas diferenciadas na unidade do continente africano; além disso, o Corão apela à identidade de um cordão muçulmano que, de Gibraltar à Indonésia, divide o Norte do Sul do mundo.

Nestas circunstâncias, é certamente uma das tarefas mais desafiantes para os governos que exercitam todos uma soberania em crise, e dos quais se espera uma criatividade que sirva a paz como envolvente forte da mudança, a tarefa de harmonizar tão diferenciadas e múltiplas filiações, umas baseadas na experiência e na história, e outras induzidas pelas leituras do futuro premente.

É, porém, inquietante que este quadro exigente de conciliações se debata hoje com o anúncio de uma conflitualidade dominada pelo confronto armado das várias civilizações, marcadas pelas diferenças religiosas, numa circunstância em que todas as 
áreas culturais falam pela primeira vez com voz própria na cena internacional e se vêem forçadas à convergência pela globalização derivada das revoluções científica, técnica e dos mercados.

É nossa convicção, no entanto, que a cultura e o progresso são filhos da mistura. E esta convicção funda-se na experiência que está a ser vivida, no campo das migrações, pela Comunidade de Povos de Língua Portuguesa (CPLP), e também no campo das suas distintas literaturas, e ainda no desígnio comum de participação conjunta na construção da sociedade do conhecimento, todavia num contexto de particulares políticas da língua. A curta experiência desta Comunidade tem mostrado, pensamos nós, que a convergência dos países culturalmente solidários, que prestam uma solidária homenagem a iguais valores da paz e do desenvolvimento, tornam mais forte e mais escutada a voz com que afirmam a sua presença na ordem internacional em mudança.

As solidariedades horizontais (que decorrem da partilha de uma mesma língua e da miscigenação de memórias e tradições, identificando uma e outra a área cultural lusófona) são, neste sentido, ao que pensamos, um elemento que fortalece o tecido da globalização das dependências, assim contribuindo para uma articulação entre a linha da territorialização dos poderes políticos e a linha da mundialização da sociedade civil organizada em rede.

Com certeza que é inevitável que cada um dos países lusófonos reunidos na CPLP tenha de considerar a ligação a grandes espaços diferenciados e que conjunturalmente tenha de considerar também a ligação a espaços com interesses que, nuns casos se podem conjugar, por serem contíguos, como é o caso do espaço ibero-americano de expressão castelhana, e noutros se podem negociar, por serem eventualmente contraditórios, como no caso do espaço anglo-saxónico, que é hoje o espaço hegemónico. Todavia esta realidade múltipla, tornando mais complexa a tarefa da solidariedade dos povos, torna igualmente mais estimulante e exigente o seu exercício. Uma política editorial a ser pensada em termos linguísticos para a grande área cultural e política do espaço lusófono, e também ibero-americano, tem que contar com este desafio e esta exigência. 


\section{A sociedade do conhecimento, a lusofonia e o espaço ibero-americano}

Ao reflectir sobre a lusofonia, há que assinalar a multidão de pessoas que tem a língua portuguesa como primeira língua. São 190 milhões os falantes de português, quase tantos como os falantes de francês (110 milhões) e de alemão (100 milhões) juntos. Depois do mandarim, com 1000 milhões de falantes, do hindi com 460 milhões, do espanhol com 300 milhões, do inglês com 350 milhões e do árabe com 200 milhões, o português vem a seguir, em sexto lugar. No entanto, na era da informação global, impressiona saber que o total de falantes em língua inglesa é de 1000 milhões, enquanto o Hindi é 650 milhões, o Francês 500 milhões, o Árabe 425 milhões, o espanhol é 320 milhões, o russo 280 milhões e o português 230 milhões. Mas, em contrapartida, os utentes da Internet de língua inglesa são 28\% do total, os de língua chinesa 23\%, os de língua espanhola $8 \%$, os de língua japonesa $5,3 \%$, à frente dos utentes de Internet de língua portuguesa, com apenas 4,3\% do total. Curioso é notar que os utentes de língua francesa e de língua árabe andam ambos ligeiramente acima dos $3 \%$, ultrapassados pelos de língua alemã com 4\%. O Hindi não vem assinalado no top 10 das línguas na Internet, integrando a categoria 'All de rest', que se cifra em 17,2\%.

\begin{tabular}{c|c|c}
\hline Language & Native speakers & Total of speakers \\
\hline Mandarin & $1,000 \mathrm{M}$ & $1,051 \mathrm{M}$ \\
\hline English & $350 \mathrm{M}$ & $1,000 \mathrm{M}$ \\
\hline Hindustani & $460 \mathrm{M}$ & $650 \mathrm{M}$ \\
\hline French & $110 \mathrm{M}$ & $500 \mathrm{M}$ \\
\hline Arab & $200 \mathrm{M}$ & $425 \mathrm{M}$ \\
\hline Spanish & $300 \mathrm{M}$ & $320 \mathrm{M}$ \\
\hline Russian & $165 \mathrm{M}$ & $280 \mathrm{M}$ \\
\hline Portuguese & $190 \mathrm{M}$ & $230 \mathrm{M}$ \\
\hline German & $100 \mathrm{M}$ & $150 \mathrm{M}$ \\
\hline
\end{tabular}

Fonte: http://wapedia.mobi/pt/L\%C3\%ADngua_mundial [valores em Dezembro de 2009] 
A globalização e o paradigma comunicacional da sociedade em rede, por ela reclamado, baseado na convergência dos meios de comunicação e na ampla utilização de tecnologias da informação, convocam entretanto um novo lugar para a lusofonia ${ }^{4}$. O ciberespaço permite, com efeito, o estabelecimento de redes virtuais de comunicação entre cidadãos que pensam, sentem e falam em português. A questão a que a comunidade científica está, todavia, convidada a responder é a de saber o que é que acrescenta à experiência da lusofonia este novo espaço onde cidadãos das mais diversas proveniências se (re)encontram para partilhar informação, experiências, ideias e memórias ${ }^{5}$. A política editorial sobre as publicações científicas de expressão portuguesa não pode ficar indiferente a este debate.

\section{Top 10 Languages in the Internet in millions of users}

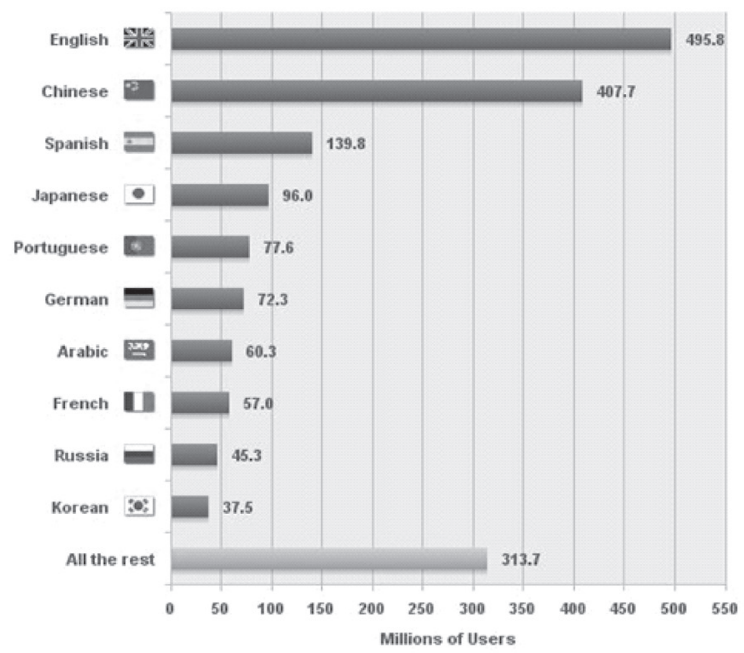

Fonte: Internet WorldStats - www.internetworldstats.com/stats7. html [estimativa dos usuários da Internet, em 31 de Dezembro de 2009: 1802330 457]

\footnotetext{
${ }^{4}$ Sobre este assunto, ver Martins (2011) Globalization and Lusophone World. Implications for Citizenship.

${ }^{5}$ Sobre uma cartografia do ciberespaço lusófono, veja-se o artigo colectivo Macedo etalii (2010): “Por mares nunca dantes navegados': contributos para uma cartografia do ciberespaço lusófono”).
} 
Mas não é apenas na Internet que o inglês se impõe a todas as línguas. Como segunda língua, o inglês esmaga toda a concorrência. $\mathrm{O}$ inglês é apenas a quarta língua nativa mais falada, depois do chinês, do hindi e do espanhol, embora se pense que mais de mil milhões de pessoas falem um inglês de maior ou menor fluidez.

Quando falamos de transmissão de conhecimento, por meio de revistas (e também de livros), publicadas em papel, ou então online, não podemos deixar de ter em atenção que a informação se faz em línguas, que é sempre precisa uma língua vernácula para o divulgarmos. À medida, todavia, que o mundo se torna mais global, que a velocidade dos transportes encolhe as distâncias geográficas, que as redes de telecomunicações se espalham em maior largura de banda, a pressão por uma só língua aumenta. Pensamos, todavia, que todos aqueles que se acham comprometidos com a língua portuguesa têm que entrar nesse combate ${ }^{6}$. Preservar uma língua, expoente máximo de uma cultura, é sem dúvida saber fortificá-la na comunicação diária e global. Mas é, igualmente, saber fortificá-la como língua de pensamento e na transmissão do conhecimento. Neste sentido, é dever de todos os falantes de uma língua, seja na comunicação diária, seja na comunicação científica, cultivá-la e promovê-la, porque é na língua em que sentimos, pensamos, nos exprimimos e comunicamos, que se joga afinal a identidade de um povo, de uma cultura, de uma civilização.

\section{Uniformização linguística e combate linguístico}

O inglês é hoje, indiscutivelmente, a língua dominante no mundo, tal como outrora o foram o latim e o francês. Contrariamente, todavia, ao latim que no Império romano era sobretudo a língua da administração, o inglês tem hoje uma força de carácter preponderantemente económico, político, cultural e científico. Ou seja, além de ser a língua franca do comércio e da cultura de massas (cinema, televisão, música), o inglês é também a língua franca da tecnologia, e das tecnologias da informação, e ainda a língua do conhecimento. E são de assinalar duas grandes vantagens que o inglês tem sobre as outras línguas: por um lado, tem a vantagem

\footnotetext{
${ }^{6}$ Ver, a este propósito, Pierre Bordieu (1982), Ce que parlerveutdire.
} 
da distribuição geográfica enquanto língua nativa; e, por outro lado, a vantagem de ser língua oficial de países muito povoados. Os falantes do português concentram-se na América do Sul, na Europa e na África, ao passo que o inglês é falado como língua materna nestes três continentes e na Oceania (Austrália e Nova Zelândia). Depois, são de destacar os países de África e Ásia, onde a história deu ao inglês um papel fundamental como língua oficial; em África destacam-se a Nigéria, a África do Sul e o Quénia; e na Ásia, a Índia, o Paquistão, o Bangladesh e Hong-Kong (China) ${ }^{7}$.

A difusão geográfica e temática do inglês, a uma escala global, concorre, no entanto, para um enfraquecimento de todos os vernáculos, e portanto também do português. Podemos dizer, além disso, que as novas realidades, científicas, tecnológicas, culturais e sociais, ao serem expressas com termos ingleses, vêem acentuar- se esse empobrecimento da língua vernácula. Assistimos hoje, com efeito, a uma verdadeira invasão das línguas vernáculas, não apenas por novos termos (breefing, workshop, meeting, marketing, design, etc.), mas também por semantizações estranhas.

Nestas circunstâncias, preservar a língua própria, no caso a língua portuguesa, expoente máximo da cultura, é saber fortificá-la, tanto na comunicação diária, como na comunicação global. E da mesma forma que os profissionais da comunicação social, assim como os professores de língua e cultura portuguesa, devem entender-se como instrumentos activos dessa fortificação, assim também as revistas científicas de Ciências Sociais e Humanas, entre as quais as revistas de Ciências de Comunicação, devem desempenhar papel equivalente no mundo académico. $\mathrm{O}$ intercâmbio editorial entre Portugal e o Brasil, e também o intercâmbio entre Portugal e os países africanos de expressão oficial portuguesa, continua todavia a ser incipiente. Mas a língua deve funcionar nestes países, não apenas como um importante instrumento comercial e político; ela deve funcionar, de igual modo, como um meio estratégico de afirmação lusófona, seja em termos culturais, seja em termos científicos ${ }^{8}$.

\footnotetext{
7 Seguimos de perto, neste tópico, Fidalgo (2008), "As línguas ibérias face à informação global".

8 No sentido de "uma análise crítica da cultura e dos média", ver Matins et al. (2006) Comunicação e lusofonia.
} 
Com efeito, uma língua apenas pode fazer valer a sua força pela informação, pelo pensamento e pelo conhecimento que veicula. Ora, esta força da língua tanto deve ser demonstrada pela imprensa escrita, pela rádio e pela televisão, como também o deve ser em termos literários, e ainda em termos científicos. A produção editorial, particularmente a publicação de revistas científicas, não pode, todavia, descurar a sua conversão online, dado o facto de a importância de uma língua se medir pelos conteúdos disponibilizados neste meio.

Contra o empobrecimento da língua, é hoje, pois, função de primordial importância na política editorial a escrita em língua portuguesa. $\mathrm{O}$ combate linguístico tem várias frentes. Assim como a comunicação social tradicional, e também a comunicação na Internet, deve disponibilizar em vernáculo a maior variedade de informação, literária, científica, cultural, visual, musical, económica, tornando- a acessível ao maior número de falantes, nativos e não nativos de uma língua, assim também as revistas científicas devem transmitir pensamento e conhecimento,urbi et orbi, em língua vernácula. E do mesmo modo que cabe à comunicação social e aos professores de língua e cultura empenharem-se neste combate pela sobrevivência da língua portuguesa, assim também é um desafio para os investigadores de Ciências Sociais e Humanas do espaço lusófono, e de entre estes destacamos os investigadores de Ciências da Comunicação, empenharem-se neste combate pela nossa sobrevivência plural, na diversidade dos povos e culturas que somos.

\section{Referências}

BOURDIEU, Pierre. Ce que parler veut dire. Léconomie des échanges linguistiques. Paris: Fayard, 1982.

BRITO, Regina; MARTINS, Moisés de L. Considerações em torno da relação entre língua e pertença identitária em contexto lusófono. Anuário Internacional de Comunicação Lusófona, 2, São Paulo: LUSOCOM - Federação Lusófona de Ciências da Comunicação, 2004.

CABECINHAS, R.. CUNHA, L. (Eds.) Comunicação intercultural: Perspectivas, Dilemas e Desafios. Porto: Campo das Letras, 2008. 
FIDALGO, António. As línguas ibérias face à informação global. In: SIERRA, F.; MARTINS, M.de L.; GÓMEZ, F. (Eds.), Comunicación y desarrollo cultural en la Península Ibérica: retos de la sociedad de la Información. Actas del III Congreso Ibérico de Comunicación, Universidad de Sevilla, 2008. pp. 43-53.

MACEDO, Lurdes; MARTINS, Moisés de Lemos; MACEDO, Isabel. Por mares nunca dantes navegados: contributos para uma cartografia do ciberespaço lusófono. Anuário Internacional de Comunicação Lusófona - 2010, Braga, p.11-39, 2010.

MARTINS, Moisés de L.. Globalization and Lusophone World. Implications for Citizenship. In: PINTO, M.; SOUZA, H. (Eds.) Communication and citizenship - Rethinking crisis and change. (IAMCR Conference, 2010). Coimbra: Grácio Editor/CECS, 2011. pp. 75-84.

MARTINS, Moisés de L.; SOUZA, H.; CABECINHAS, R. (Eds.). Comunicação e lusofonia: para uma abordagem crítica da cultura e dos media. Porto: Campo das Letras, 2006.

Sites:

http://wapedia.mobi/pt/L\%C3\%ADngua_mundial www.internetworldstats.com/stats7.htm 